\title{
As identidades da atleta brasileira: os "pontos de apego temporários" da mulher na vida esportiva
}

\author{
Marcio Antonio Tralci Filho* \\ Katia Rubio**
}

\begin{abstract}
Resumo: O objetivo desse trabalho é analisar a formação das identidades de atletas olímpicas brasileiras e a construção desse papel social tanto no cenário olímpico como no contexto social brasileiro. Os resultados obtidos, quando confrontados com a literatura da área e o referencial teórico adotado, permitem inferir que, mesmo após a crescente inclusão de mulher brasileiras em diversas modalidades esportivas ressaltando que essa inclusão não se deu sob a forma de enfrentamento, tal qual em outros países - isso não representou um repensar dos papeis sociais do feminino e do masculino, cabendo às atletas sustentar uma separação entre a vida de atleta e a vida enquanto mulher.
\end{abstract}

Palavras-chave: Estudos Culturais. Crise de Identidade. Olimpismo. Gênero.

\section{INTRODUÇÃo}

Os Jogos Olímpicos de 1896, os primeiros da Era Moderna, foram permitidos às mulheres apenas na condição de espectadoras do espetáculo e proibidas de competir por motivos de ordem biológica (RUBIO; SIMÕES, 1999, p. 53). Porém, na edição seguinte, as mulheres foram formalmente aceitas como participantes nas competições de golfe e de tênis, modalidades consideradas belas esteticamente, e que não ofereciam contato físico entre as participantes (CRUZ, SILVA; GOMES, 2006, p. 13).

\footnotetext{
"Mestrando na Escola de Educação Física e Esporte da Universidade de São Paulo (USP). Email: matfilho@gmail.com

"Professora Associada da Escola de Educação Física e Esporte da Universidade de São Paulo (USP). E-mail: katrubio@usp.br
} 
Contudo, é na década de 1920 que a luta das mulheres pelo seu espaço no mundo esportivo ganha força. É nesse momento que ocorre o embate entre a atleta Alice Milliat, presidente da Federação Francesa de Desporto Feminino, e o presidente do Comitê Olímpico Internacional (COI), o Barão de Coubertin, que nega veementemente a inclusão do programa completo de atletismo feminino nos Jogos da Antuérpia em 1920, proposto por Milliat. Como resposta, foi organizado, no ano posterior, os I Jogos Femininos e a criação da Federação Internacional Desportiva Feminina, também por Milliat. Em 1922 ocorre a segunda edição desses Jogos, agora com a denominação "Jogos Mundiais Femininos" que também eram autodenominados Olímpicos. O impacto desse evento foi tão grande que abriu as portas para uma negociação de Milliat com a Federação Internacional de Atletismo para a inclusão do programa completo de atletismo feminino nos Jogos de Amsterdã (1928), com a contrapartida de retirar a denominação "Olímpicos" dos Jogos Femininos. O acordo foi cumprido unilateralmente, já que houve apenas cinco provas do atletismo: 100 metros, 800 metros, revezamento 4 por 100 metros, lançamento de disco e salto em altura (CRUZ, SILVA; GOMES, 2006, p. 17).

Consequentemente, nos Jogos de 1928, ocorre uma demonstração clara de enfrentamento, das mais significativas, quando a equipe feminina britânica de atletismo realizou o primeiro boicote da história dos Jogos ao se recusar de participar de um programa tão reduzido (CRUZ, SILVA; GOMES, 2006, p. 15). A percepção da condição desigual a qual estavam submetidas e o seu consequente enfrentamento e questionamento estavam presentes já no princípio no esporte olímpico feminino europeu, sendo possível que tais mobilizações tenham contribuído na construção da identidade das atletas em certos países daquele continente.

O Brasil entrou para o cenário olímpico em 1920, nos Jogos Olímpicos de Antuérpia, e contou com uma delegação composta por 21 atletas, todos homens. Contudo, foi na terceira participação 
olímpica do Brasil, em Los Angeles 1932, que uma mulher participou da delegação: a nadadora Maria Lenk. Era a primeira mulher latinoamericana a participar dos Jogos Olímpicos (CARDOSO, 2000, p. 504).

Entretanto, isso não representou a massificação da prática esportiva entre as mulheres brasileiras. Uma evidência contundente disso é o fato de as primeiras medalhas olímpicas para o esporte feminino brasileiro foram conquistadas apenas em 1996, nos Jogos de Atlanta, com o vôlei, vôlei de praia e basquetebol. Nesse sentido, carecem estudos que investiguem o processo de formação de identidade da mulher no âmbito do esporte olímpico brasileiro buscando com isso compreender a dinâmica de inclusão e a representatividade social lograda pelas atletas. Tal empreitada se justifica em um esforço de se compreender - não se esquecendo que manifestações de enfrentamento coletivo e a conquista litigiosa do espaço das mulheres no contexto olímpico não fizeram parte da história esporte feminino brasileiro - como esse hiato entre a primeira participação e as primeiras medalhas pode ter causado reflexos no entendimento que as atletas expressam em relação ao seu papel social ou às suas "posições-de-sujeito".

O objetivo desse estudo é, portanto, analisar aspectos das identidades de atletas mulheres olímpicas brasileiras e a construção desse papel social tanto no cenário olímpico como no contexto social brasileiro. Para tanto, serão consideradas questões específicas como a inserção da mulher no cenário e no contexto olímpico, os discursos das protagonistas que ocuparam e ocupam o papel social de "atletas olímpicas", e as referências que tangenciam os conceitos de identidade.

\section{Decisões metodológicas}

Essa pesquisa utiliza como metodologia as histórias de vida, conforme Bosi (1994; 2003) e Rubio (2006), a partir das narrativas colhidas junto às protagonistas da participação brasileira em Jogos 
Olímpicos. A narrativa aqui é tomada como linguagem a partir da dimensão adotada pelos Estudos Culturais (HALL, 2000; 2006), tida como uma posição privilegiada na construção e circulação do significado, conforme Guareschi, Medeiros e Bruschi (2003) e Silva (2000). É também a partir da referência conceitual dos Estudos Culturais que se pretende analisar a identidade da mulher brasileira no esporte olímpico, considerando que o referencial proposto leva em conta a cultura como principal eixo articulador.

Stuart Hall (2000, p. 112) define identidade como "pontos de apego temporário às posições-de-sujeito que as práticas discursivas constroem para nós" e afirma que as mudanças ocorridas no século XX foram substanciais para a ruptura da noção de sujeito unificado que se tinha do indivíduo moderno. A "crise de identidade" é o que resulta dessa fragmentação na qual os indivíduos perdem as referências que, até então, lhes davam "ancoragem estável no mundo social" (HALL, 2006, p. 07), passando a se afastar cada vez mais da identidade única e se aproximar de identidades múltiplas, baseadas nas diferenças ao invés da unidade (RUBIO, 2006, p. 35). Há de se sublinhar que a participação de mulheres em esportes historicamente considerados masculinos está inserida nessa ruptura do indivíduo moderno evidenciada por Hall.

As narrativas foram coletas em forma de entrevistas presenciais gravadas em mídia audiovisual e, posteriormente, transcritas. Selecionamos esportistas de todo o país e das mais diversas modalidades, compondo um banco de dados de, aproximadamente, setenta atletas. Dessas, sete foram selecionadas para esse artigo pela importância que dão, em suas narrativas, às questões que envolvem o ser mulher no esporte. Dentro desse recorte encontramse atletas que participaram das edições dos Jogos Olímpicos de Munique, em 1972, até os Jogos de Pequim, em 2008, em diversas modalidades (atletismo, futebol, hipismo, iatismo, judô e natação). Optou-se, ainda, após uma breve descrição de suas histórias de vida, por trazer trechos desses discursos ao longo do texto do artigo, em vez de separar uma parte específica de "resultados", pois consideramos que eles permitem complementar e ilustrar as 
discussões realizadas a partir da análise da literatura e referenciais teóricos da área. As atletas não terão seus nomes revelados e, quando citadas, estes serão substituídos por letras não correspondentes às suas iniciais.

\section{Análise e discussão}

\subsection{PROCESSOS DE CONSTRUÇÃO DAS IDENTIDADES DAS MULHERES BRASILEIRAS POR MEIO DAS PRÁTICAS CORPORAIS}

Levando em consideração que a questões de gênero e o feminismo, tanto como corrente epistemológica quanto como movimento social, se tornaram pontos nevrálgicos no contexto político, público e privado, ao longo do século XX (HALL, 2006; HOBSBAWM, 2008), faz-se imprescindível verticalizar a discussão acerca das relações de gênero que se fazem presentes também no âmbito esportivo. Com o intuito de tecer considerações sobre os elementos que colaboraram na construção do processo de construção das identidades das atletas, trazemos à tona alguns dados e reflexões encontrados em Goellner e Fraga (2004) e no Regulamento $n^{\circ} 7$ (1934). Ao final do século XIX, ainda era observada com cautela a inclusão da mulher na prática de exercícios físicos, porém, é nesse período que ocorrem as primeiras medidas que levam em consideração os benefícios das práticas corporais em relação ao corpo feminino. Tais propostas, contudo, não podem ser consideradas emancipatórias, uma vez que não promoveram uma mudança dos pontos de vista em relação à aproximação da mulher e seu corpo em movimento (ADELMAN, 2003). Talvez a relação entre masculino e feminino e os espaços públicos e privados e a "publicidade" do corpo da mulher fosse um dos principais entraves a uma postura menos retraída e preconceituosa das instâncias discursivas da época.

Goellner e Fraga (2004) comentam as idéias de Fernando de Azevedo, intelectual do começo do século XX, que em suas obras Da Educação Physica e Antinoüs: estudo da cultura atlhetica, 
ambas de 1920, inicia uma trajetória científica e teórica em relação à Educação Física e atividade motora. Nessa ocasião, Azevedo propôs a instituição da Educação Física como ciência se integrando aos ideais da nação. Seus propósitos se baseavam em teorias médicas higienistas e eugênicas vigentes, as quais deveriam voltar-se para a melhoria dos indivíduos fracos a fim de se criar um contingente mais preparado e capaz e, desse modo, construir os alicerces para a manutenção de uma nação saudável, protetora e perpetuadora da espécie, firmando as "virtudes da raça". Desse modo, além de cuidar do corpo-materno, o exercício concatenaria essa característica ao bem estar de toda a Nação, à sua proposta de "corpo-nação". Assim como explana Luce Irigary citada e traduzida por Goellner e Fraga (2004): "nesta sociedade a mulher existe apenas como uma ocasião para a mediação, transação, transição, transferência, entre homens e mesmo entre o homem e ele mesmo".

Não muito distante ${ }^{1}$ está o Regulamento $\mathrm{n}^{\mathrm{0}}$ 7, ou o "Método Francês"2, que propõe uma Educação Física especial para as mulheres a qual não deveria ir além das supostas determinações biológicas impostas a elas. Consideravam os seres humanos iguais, em relação às características sexuais, até os sete anos, porém, "no momento da puberdade, enquanto o rapaz procura instintivamente ocasiões de produzir esforços musculares intensivos, a mulher tornase, ao contrário, mais calma e mais reservada. Sua educação física deve ser essencialmente higiênica" (REGULAMENTO nº 7, 1934, p. 16). Continua a restrição a certas práticas pelas mulheres argumentando que "a menstruação durante a adolescência e, mais tarde, a gravidez e o aleitamento, tornam-se causas de esgotamento, quando lhes acrescenta a fadiga muscular" (REGULAMENTO $\mathrm{n}^{\circ}$ 7, 1934, p. 16) e que "a mulher não é constituída para lutar, mas para

\footnotetext{
'De fato, Castellani Filho (2006, p. 75-76) evidencia que Fernando de Azevedo deixou clara a sua opção pelo Método Francês em um artigo intitulado "O papel do Professor moderno de Educação Física".

${ }^{2}$ Esse método fora adotado em larga escala nas aulas de Educação Física Escolar no território nacional durante a década de 30 do século passado. Para maiores detalhes, consultar GOELLNER, S. V.. O Método Francês e a Educação Física no Brasil: da caserna à escola. 1992. 215 f. Dissertação (Mestrado) - Escola Superior de Educação Física, Porto Alegre, 1992.
} 
procriar" (REGULAMENTO n 7, 1934, p. 16). Recomendavam para as mulheres as seguintes práticas:

A marcha, os exercícios rítmicos e de suspensão de curta duração com tempos de impulsão, o salto na corda, o lançamento de disco, dardo e peso (menor que os dos homens), os jogos de raquete (péla e tênis), o transporte de pesos leves em equilíbrio na cabeça, e esgrima dos dois braços, que exigem em definitivo apenas um trabalho moderado e que põem em ação, sobretudo, os músculos da bacia, serão, em princípio, os exercícios próprios à mulher. Qualquer exercício que seja acompanhado de pancadas, de choques e de golpes, é perigoso para o órgão uterino. A higiene condena sua prática pela mulher (REGULAMENTO n ${ }^{\circ}$ 7, 1934, p. 16).

Deve-se ressaltar o fato de que esses discursos não justificaram as práticas corporais pelas mulheres apenas nesses períodos citados. A evocação do corpo naturalizado da mulher é recorrente em trabalhos acerca da dita "educação física feminina" em momentos posteriores, como visto no artigo A importância da aptidão física para a mulher em edição de 1976 da Revista de Educação Física do Exército assinado pelo Capitão Paulo Roberto Laranjeiras Caldas e pelo $2^{\circ}$ Sargento Israel Gomes Filho, ambos pertencentes ao corpo docente da Escola de Educação Física do Exército. Nessa oportunidade, os oficiais apontam diversas diretrizes sobre o trabalho a ser realizado com as mulheres, sendo que uma delas orienta que "os exercícios brutais devem ser abolidos, pois a mulher não foi constituída para lutar, mas para procriar" (CALDAS; GOMES FILHO, 1976, p. 10).

Oriunda de uma família de esportistas - declarando, inclusive, que sua mãe fora uma das grandes concorrentes de Maria Lenk nas seletivas para os Jogos de 1936 - T. I. iniciou sua prática no hipismo por intermédio de seu pai e colegas e com quinze anos já competia no adestramento sob a tutela rigorosa de um treinador alemão. Após ser diversas vezes campeã paulista e brasileira, com dezoito anos, se muda para a Alemanha e passa a morar com a primeira medalhista da história dos Jogos Olímpicos (a prova do adestramento é mista, 
com predominância masculina). Em 1972, com 23 anos, foi a atleta mais jovem do adestramento dos Jogos Olímpicos, competindo com uma amazona de 75 anos. No trecho a seguir, T. I. relata como o seu pioneirismo em um esporte oriundo de atividades militares - e, não por acaso, permeado por concepções centradas na exaltação da masculinidade - resultou em tensões perante seus colegas cavaleiros:

Normalmente quem ganhava eram os militares. E homens. Tive que montar muito para poder ganhar dos homens e dos militares. Eu fui a primeira mulher a dar aula de adestramento na Hípica Paulista. No picadeiro da Hípica eu era atropelada por outros cavaleiros, porque achavam um absurdo uma mulher dar aula. E havia muito preconceito de montar com uma professora mulher, por causa da relação entre cavalo e hombridade. Então, como é que uma mulher pode ensinar um homem?

É bastante provável que esses pensamentos passaram a ser, pela aceitação que obtiveram à época, o balizamento para a difusão das práticas corporais às mulheres e para políticas públicas nas décadas seguintes. Como nos mostra Castellani Filho (2006, p. 60), essas instituições, autores e legisladores acabaram por enfatizar o pensamento dominante em relação à representação social da mulher ao sugerirem a preparação de seus corpos para a maternidade. É de nosso conhecimento que existiu também um reforço legal das restrições às práticas esportivas pelas mulheres com a proibição de praticarem modalidades "incompatíveis com suas características", como o decreto-lei n 3.199 de 1941 e a deliberação no 7 de 1965 do Conselho Nacional de Desportos, a qual especificava tais modalidades (CASTELLANI FILHO, 2006, p. 61-63).

P. D. começou a praticar Judô por incentivo do pai que considerava esse esporte não somente bom para a melhora da saúde dos filhos, como para sua integração social. Antes de entrar em contato com essa prática, ela fazia Balé sob o incentivo da mãe, porém considerava a dança monótona. No começo acreditava que o Judô era um esporte voltado para os meninos, mas em pouco tempo 
começou a se interessar mais seriamente. Quando já havia sido convocada para a Seleção Brasileira Júnior, acompanhou as lutas de Rogério Sampaio pela televisão nos Jogos Olímpicos de 1992 e, a partir desse momento, se interessou pelo megaevento que nunca havia assistido antes. Após obter ótimo resultado nos Jogos Panamericanos de 1999 se lesionou e não participou dos Jogos Olímpicos de 2000, adiando sua estreia para 2004. Apesar de não ter vivido sob o período da proibição legal, a atleta verticaliza a discussão ao comentar os efeitos de tal política pública:

No Judô acho que a gente vive uma problemática ainda maior. Como a gente tinha aquela lei que todo mundo conhece, até 1979, que não permitia a prática em vários esportes, o judô não podia ser praticado a nível competitivo, aliás, a nível nenhum, mas ainda tinham mulheres que praticavam "clandestinamente". Mas eram poucas meninas que praticavam. Se juntar o Brasil inteiro, não se conseguia acima de trinta, acho que não, acho que eu estou sendo muito otimista com isso.

Louro (1997) analisa que é dessa idéia de determinismo biológico que surge a necessidade, por parte de feministas anglo-saxãs, de se utilizar o termo "gênero" em contraposição ao "sexo". Se é possível afirmar que existem diferenças sexuais entre homens e mulheres, a construção social que é elaborada a partir desses elementos pertence ao campo do gênero. Assim, o que se pretende é trazer para o campo político o que se insiste em manter no campo da biologia e da naturalização das desigualdades, uma vez que é no âmbito das relações sociais que se constroem as concepções de feminilidade e masculinidade. Esse conceito gera uma grande transformação nos Estudos Feministas e passa a ser utilizado, não sem disputas e tensões, por feministas brasileiras no final da década de 80 (LOURO, 1997, p. 23).

Ao longo do período posterior o que se viu foi a transformação da linguagem sobre o corpo e as habilidades motoras, já que a mulher provocou o deslocamento de uma condição social e de um papel no tempo e no espaço. Contudo, esse deslocamento não se deu de forma 
revolucionária na derrubada dessa conceitualização a respeito dos fatores impeditivos ou restritivos para as práticas esportivas pelas mulheres. Nas palavras de Goellner (2005, p. 145):

$\mathrm{Na}$ fase de estruturação do esporte feminino no país, idéias progressistas e moralistas seduziam e desafiavam as mulheres, tanto para a exibição quanto para o ocultamento de seus corpos, ora forjando novas formas de cuidar de si, ora reforçando a idéia de que a exibição pública do seu corpo estava associada ao universo pagão das impurezas e obscenidades. Se por um lado, havia a crítica à indolência, à falta de exercícios físicos, ao excesso de roupas, ao confinamento no lar, por outro, ampliavam-se as restrições a uma efetiva inserção feminina em diferentes espaços públicos o que, de certa maneira, cerceava alguns possíveis atrevimentos.

Cabe notar que, a partir dos anos 70, o discurso da "erotização" do corpo feminino uniu-se - e não substituiu - ao da manutenção da saúde para a maternidade. A inevitável participação feminina nas mais diversas modalidades esportivas foi acompanhada por uma preocupação em manter um ideal de sensualidade feminina (GOELLNER, 2005) ${ }^{3}$, por meio da espetacularização de seus corpos em academias de ginástica, estádios e ginásios. O corpo exercitado das mulheres, principalmente das atletas, passa a ser objeto de desejo social. E esse parece ser o paradigma do esporte feminino que ainda persiste nos tempos atuais. É o que relata uma jogadora de futebol quando da elaboração do campeonato "Paulistana", em 2001, cuja história de vida a nós contada está resumida a seguir.

C. J. começou a jogar futebol com os meninos da vizinhança. Seu pai queria que o irmão dela fosse jogador, mas foi a filha que se

\footnotetext{
${ }^{3} \mathrm{~A}$ autora faz referência a uma reportagem da Revista Veja, assinada por Maurício Cardoso e intitulada "Flores do Campo", tratando da equipe feminina de futebol dos Jogos Olímpicos de Atlanta (1996), para ilustrar que, à beira do século XXI, a erotização dos corpos das mulheres é parte integrante do espetáculo esportivo. Segue o trecho citado pela autora: "Como no futebol masculino, a competência dos jogadores é fundamental para transformar o esporte em um empreendimento comercial. Mas no jogo das mulheres, ao contrário do dos homens, isso não é suficiente. Os clubes estão exigindo que além de saber bater sua bolinha as jogadoras sejam bonitas" (CARDOSO, 1996, p. 72).
} 
demonstrou mais habilidosa para o esporte. Sua mãe, que não gostava da ideia de ter uma filha praticando futebol, impôs uma série de tarefas domésticas que ela deveria realizar antes de sair para a rua. Contudo, com a ajuda do irmão, ela sempre terminava a tempo de brincar. E foi em pouco tempo que sua vida mudou: aos treze anos sua mãe faleceu e ela saiu de casa para se juntar ao time da Seleção Olímpica de Atlanta. Em pouco mais de dez anos de carreira, se destacou com as equipes que participaram de campeonatos Sulamericanos, Pan-americanos e dos Jogos Olímpicos de 2000 e 2004. Ressaltamos, pois, a clareza com que trata da exibição de seu corpo no espetáculo esportivo:

Todas as equipes usavam uniformes que eram um parâmetro para todos. Eram shorts extremamente curtos, não tinha como praticar a modalidade, ainda mais eu que sou zagueira, que costumo dar muito carrinho. O primeiro carrinho que eu desse eu ficava sem roupa. Uma camiseta minúscula, tudo isso para levar homens para o estádio e para os homens olharem as mulheres e não em si o futebol.

\subsection{As IDENTIDADES: DA PERCEPÇÃO DA DISCRIMINAÇÃO À MANUTENÇÃO DA FEMINILIDADE}

Em um artigo de relevância para esse estudo, Adelman (2003), nos apresenta a posição da historiadora Mary Jo Festle que afirma que as mulheres atletas sempre tiveram de encarar, ao menos, dois tipos de preconceito social. O primeiro refere-se às "diferenças físicas" entre mulheres e homens que as tornavam menos competentes para o esporte. Temos aí que as diferenças acabam por se tornar subterfúgios restritivos, quando não impeditivos, da prática esportiva, transformando as peculiaridades inerentes e construídas das mulheres em desigualdades. O segundo, diz respeito ao fato de que a prática esportiva masculinizava as atletas, questionando sua "normalidade" ou sexualidade. Festle (1996 apud ADELMAN, 2003, p. 448) argumenta ainda que atletas profissionais não vêem outra alternativa se não adotar uma postura defensiva, "tomando o cuidado necessário de mostrar para o público que sua 
prática no esporte não compromete sua feminilidade". Esse questionamento ao esporte feminino é trazido à tona novamente por C. J.:

Essa comparação entre o masculino e feminino acho que vai existir sempre. Mas é completamente diferente. Normalmente em preparação a gente joga contra o time masculino mesmo. Os meninos ficam bastante invocados, porque levam "rolinho"4.

Homossexualismo não existe só no futebol feminino, mas por que só se fala no futebol feminino? Porque a imagem é essa. Você não precisa ser uma "mulherhomem" para jogar futebol, mas infelizmente a imagem que é passada é assim.

E novamente trazemos a análise de Louro (1997, p. 23) que afirma que, apesar de estarem relacionadas, identidades sexuais e identidades de gênero não podem ser confundidas. Enquanto que as primeiras se referem ao fato de os sujeitos exercerem sua sexualidade de diferentes formas - com parceiros do mesmo sexo, do sexo oposto, de ambos os sexos ou sem parceiros - as segundas dizem respeito a como que os sujeitos se consideram, social e historicamente como masculinos ou femininos.

Tal análise torna-se pertinente quando observamos o discurso das atletas brasileiras que, enquanto afirmam sua competitividade e a necessidade de estarem presentes no esporte, confirmam a desejabilidade social ao não esquecer seu "lado mulher", sua feminilidade. Conciliar o exercício do esporte com o do "ser mulher" parece não ser compatível para as atletas.

S. L. gostava de praticar diversos esportes quando criança, sonhou em ser bailarina, mas foi o atletismo, que começou a treinar na escola, que lhe despertou maior interesse. Quando competiu na cidade de Presidente Prudente, pelos Jogos Regionais do estado de São Paulo, foi selecionada por um treinador para fazer um teste. A partir daí se distanciou da família para morar na cidade. Após ganhar

\footnotetext{
${ }^{4}$ Em São Paulo, "rolinho" é o nome dado ao drible no qual um jogador passa a bola entre as pernas do adversário e, na sequência, a recupera.
} 
diversos campeonatos nas provas de curta distância, encarou o desafio do heptatlon, o que lhe rendeu participações em campeonatos mundiais e nos Jogos Olímpicos de 2008. S. L. leva para dentro das pistas certos cuidados com a aparência, sendo possível afirmar que, para a atleta, tais medidas são as características peculiares do esporte feminino. Ao ser questionada sobre como é ser mulher no esporte, nos revela:

É um pouco complicado, porque a gente sempre quer entrar vaidosa dentro da pista, bonita, maquiada, pelo menos na minha prova, chega na segunda prova eu já estou toda lambuzada. Não tem nem como passar maquiagem porque você sua e fica quase seis horas dentro da pista.

Nascida "à beira da represa do Guarapiranga", K. A. aprendeu a velejar com o pai por volta dos sete anos. Aos quinze, não pensava em relacionamentos amorosos, pois a construção e manejo dos barcos eram suam principais atividades. Desde o início da prática esportiva, sempre sonhou em participar de Jogos Olímpicos, mesmo quando não existiam provas femininas na Vela. Contudo, percebeu que as condições financeiras são preponderantes para o sucesso nesse esporte, fazendo com que ela se dedicasse a outras atividades. Voltou às águas somente após muito esforço em busca de parceiros e patrocinadores. Mesmo afirmando que, além das dificuldades financeiras, seu esporte é extremamente machista, conseguiu enfrentar essas barreiras e participar dos Jogos Olímpicos de 2004, realizando seu sonho de criança. O trecho de sua entrevista, que é trazido a seguir, é ilustrativo pelo tratamento que dá à questão das identidades emergentes da inclusão da mulher no meio do esporte de alto rendimento:

Na água você é um homem como todos os esportes. Na hora da atividade é de igual pra igual, mas tem essa parte fora. Na terra você tem seus cuidados. Meu patrocinador é a Nívea: protetor solar, você tem um cuidado, tá passando. Então em nenhum momento você deixa de perder sua feminilidade. Em nenhum momento. 
Nessa perspectiva, a despeito do crescente protagonismo das mulheres no esporte brasileiro, certas questões se colocam no meio do caminho entre a prática do esporte feminino em nível olímpico e a sua potencialidade enquanto uma instituição possível para a emancipação da mulher. Nesse sentido, observa-se que a mera participação gradual das mulheres nos referidos megaeventos não alterou certos papéis sociais de gênero no esporte. Vale aqui fazer uma pausa na discussão sobre as relações de gênero e esporte e se voltar para a história do feminismo do Brasil. Pinto (2003) revela que uma das características singulares do feminismo brasileiro é a presença do que denomina como "movimento de mulheres", ou seja, a demanda de mulheres por melhores condições de vida, mas sem o questionamento do viés masculino que norteia a sociedade em que viviam. Assim, a presença de mulheres nas arenas esportivas acompanhou essa peculiaridade do feminismo brasileiro: muitas das atletas não questionam as orientações desiguais em relação ao gênero frente às suas federações e confederações e não estão fundadas em organizações de mulheres atletas. Todavia, isso não as impediu de participar de eventos e modalidades impensadas para elas há algumas décadas. Tal fato se revela preponderantemente nas ações institucionais de fomento ao esporte feminino, tal qual é relatado por algumas atletas, dentre elas a judoca B. D. e a nadadora G. R..

B. D. "nasceu no tatame", já que seu pai é professor de Judô. Aos seis anos começou a treinar mais seriamente e com onze se mudou com a família para o Japão, onde morou por oito anos, mas sem deixar de se dedicar ao esporte. Desejando participar dos Jogos Olímpicos, algo que começou a cogitar na época do Ensino Médio japonês, retornou à terra natal para morar na casa de um amigo de seu pai e foi contratada pelo São Caetano, clube pelo qual, em 2006, entrou na Seleção Brasileira e participou dos Jogos Pan-americanos de 2007 e dos Jogos Olímpicos de 2008. No trecho a seguir, B. D. problematiza o discurso da falta de verbas para levar a equipe feminina para o campeonato mundial que se acercava na época em que foi entrevistada (início de 2009) e traz à tona fatores impeditivos que não estão na ordem das condições materiais: 
Eles dão essa desculpa que é verba. Acho que eles não querem levar mesmo. Porque fomos campeãs no Pan-Americano por equipes e no campeonato de Moscou. Então, não é por falta de experiência, eles poderiam acreditar um pouquinho mais no feminino. [...] Ou na questão de salários, o masculino é bem mais alto que o feminino. Enquanto o feminino ganha uma média de mil, dois mil reais, o masculino ganha de cinco a dez mil. Tem uma diferença bem grande.

G. R. iniciou sua prática na natação para ajudar no tratamento da asma, bronquite e sinusite. Seu pai, que havia sido jogador de futebol profissional, somente a deixava praticar outros esportes se continuasse na natação, que praticava a contragosto. Contudo, foi vendo Fernando Scherer e Gustavo Borges nos Jogos Olímpicos pela TV que ela se encantou pelo esporte. Com doze anos de idade começou a participar de competições, sendo vitoriosa em muitas delas. Após somente dois anos de competições passou a integrar a equipe de revezamento que ganhou a medalha de bronze nos Jogos Pan-americanos de Winnipeg. Depois desse feito, afastou-se da família para morar na Europa, onde galgou os degraus para participar dos Jogos Olímpicos de 2004. G. R. arremata a questão do preconceito institucionalizado, ainda que velado, em relação ao esporte feminino no Brasil de maneira bastante clara:

Você viver numa sociedade e ser mulher já é complicado. No esporte é mais complicado. Primeiramente a parte financeira, a gente vê várias competições em que a premiação masculina é sempre mais alta do que a feminina. Os meninos sempre são a prioridade em termos de planejamento, de treinamento. Isso é muito frustrante.

Os discursos de algumas dessas atletas que ainda estão em atividade competitiva já apresentam um panorama a respeito das consequências da inclusão da mulher no contexto olímpico sem a devida contestação do "androcentrismo" das instituições esportivas. Se agora elas circulam sem restrições flagrantes nos mesmos 
espaços que os homens, ainda persistem certos dispositivos, dentre eles o financiamento, que valorizam o esporte masculino em detrimento do feminino.

\section{ConsideraÇões finAIS - Em busca dA FRAGMENTAÇÃo}

Antes de iniciar as últimas considerações, é importante ressaltar que esse artigo, obviamente, não encerra as discussões sobre as identidades das atletas olímpicas brasileiras e, muito menos, sobre qual é o reflexo do protagonismo dessas atletas em um contexto social mais amplo. É preciso, em estudos futuros, fazer um recorte temporal mais específico ou analisar as histórias de vida das atletas em cada esporte, com o intuito de perceber as nuances que as diferentes práticas corporais acarretam para a construção das identidades das atletas e contribuindo para uma melhor compreensão das "culturas das modalidades". Entretanto, o estudo que originou esse artigo já nos permite esclarecer alguns pontos dos processos de construção das identidades das mulheres olímpicas brasileiras.

Em um primeiro momento, quando olhamos para algumas das concepções que motivaram as inclusões e proibições, poderíamos supor que a conquista do espaço se deu forma conflituosa e permeada por disputas frente aos órgãos de administração esportiva, visando a reconfiguração de tais concepções. Contudo, tanto a análise histórica da literatura, quanto os discursos presentes nas histórias de vida de algumas das atletas olímpicas brasileiras, sugerem que os processos de inclusão e apoio ao esporte feminino se deram de maneira não organizada por parte das atletas, evitando o enfrentamento. No Brasil não são encontrados movimentos como os Jogos Femininos e a Federação Internacional Desportiva Feminina de Alice Milliat ou o boicote da equipe feminina britânica de atletismo aos Jogos Olímpicos de 1928 em Saint Louis. Essa posição das atletas brasileiras, entretanto, não é um fato isolado, sendo possível vincular essa postura à própria conformação do feminismo no país. 
Temos, entre as atletas que aparecem nesse artigo, diversas histórias de vida marcadas por momentos de superação individual e pela necessidade de se mostrar merecedora de apoio perante as instituições reguladoras do esporte, isso sem contestar o viés masculino conferido ao esporte. Por vezes, ele é afirmado e validado. Contudo, a despeito das ações não organizadas, isso não quer dizer que a percepção de que o esporte feminino é menos fomentado por suas respectivas Confederações não é notada. Algumas atletas têm claro o viés favorável que os dirigentes conferem aos homens, identificando, inclusive, o preconceito de gênero.

Voltando às considerações de Hall (2006) e analisando os processos de formação da identidade das atletas - ressaltando que tais identidades giram em torno dos papéis relacionados à maternidade e, ao mesmo tempo, a manutenção da sensualidade como características essencialmente femininas - é possível supor que as mulheres atletas perdem sua "ancoragem estável no mundo social" no momento em que transgridem os estabelecimentos sociais ao praticar o esporte de alto rendimento. A "crise de identidade" surge quando são obrigadas a lidar com as tensões de treinar e participar das competições profissionalmente e corresponder aos papéis sociais tradicionalmente vinculados à mulher. Contudo, a fragmentação dessas identidades não é um impedimento à participação esportiva dessas atletas e, muito menos, é questionada ou problematizada por elas. Por vezes a pluralidade identitária é reforçada no próprio discurso das atletas. Desse modo, se consideramos que as mulheres olímpicas brasileiras apresentam múltiplas identidades, não é possível creditar essa multiplicidade a um mero acaso ou a diferenças individuais entre elas: há motivos de ordem histórica e política que deram amparo para a construção dessas identidades. Se as atletas não provocaram um movimento contestatório, elas adquiriram seu lugar no espaço público por meio de ações individuais. Essa característica do esporte feminino brasileiro, que, de certa maneira, acompanha o que se pode chamar de feminismo brasileiro, nos mostra o quão difusas se deram as conquistas das mulheres em relação à sua presença no mundo esportivo. 


\section{ArtigosOriginais}

Disso é possível considerar que, mesmo após a relativa conquista de um espaço público pelas mulheres, dos mais significativos, a referência de que estão pisando em um terreno essencialmente masculino é, constantemente, trazida à tona. Uma manifestação disso é que muitas afirmam - ao tratar da relação entre o gênero e a atividade que praticam - que, apesar de serem esportistas, não deixaram de ser mulheres. Não podemos deixar de considerar que, por outro lado, existem atletas que começam a perceber o modo como as questões de gênero atravessam a seara esportiva, sinalizando, talvez, para um possível movimento de contestação das desigualdades, quer seja da ordem do incentivo ao esporte feminino, quer seja dos papéis sociais desempenhados por homens e mulheres. 
The identities of the Brazilian female athlete: the "points of temporary attachment" of women in sports

Abstract: The aim of this study is to analyze the formation of the Brazilian Olympic female athletes' identities and the construction of this social role both in the Olympic scene as in Brazilian social context. The results, when compared with previous researches and the theoretical approach allows to conclude that even after inclusion of the growing Brazilian women in several sports - including pointing out that this did not occur in the form of confrontation, just as in other countries - this does not represent a rethinking of the social roles of the female and male letting to the athletes maintain a separation between sports life and life as a woman.

Keywords: Cultural Studies. Identity Crisis. Olympism. Gender.

\section{Las identidades de la atleta brasileña: Ios "puntos de apego temporales" de la mujer en el deporte}

Resumen: El objetivo de este trabajo es analizar la formación de las identidades de las atletas olímpicos brasileños y la construcción de su papel social, tanto en la escena olímpica como en el contexto social brasileño. Los resultados, en comparación con estudios previos y el enfoque teórico permiten concluir que, incluso después de la inclusión de las mujeres brasileñas en varios deportes- señalando que esto no ocurrió en forma de confrontación, al igual que en otros países - esto no ha representado un replanteamiento de los papeles sociales masculinos y femeninos, dejando en las manos de las atletas apoyar la separación entre la vida de atleta y la vida como la mujer.

Palabras clave: Estudios Culturales. Crisis de Identidad. Olimpismo. Género. 


\section{REFERÊNCIAS}

ADELMAN, M.. Mulheres atletas: re-significações da corporalidade feminina. Estudos Feministas, Florianópolis, v. 11, n. 2, jul./dez. 2003.

BOSI, E. Memória e sociedade. São Paulo: Cia das Letras, 1994.

O tempo vivo da memória. São Paulo: Ateliê editorial, 2003.

CALDAS, P. R. L.; GOMES FILHO, I. A importância da aptidão física para a mulher. Revista de Educação Física do Exército, Rio de Janeiro, n. 101, p. 8-10, 1976.

CARDOSO, M. Os arquivos das Olimpíadas. São Paulo: Panda, 2000.

Flores do campo.Veja, São Paulo, n. 1468, p.72-73, 30 out. 1996.

CASTELLANI FILHO, L. Educação física na Brasil: a história que não se conta. Campinas: Papirus, 1994

CRUZ, I.; SILVA, P.; GOMES, P. B. Deusas e guerreiras dos Jogos Olímpicos. Lisboa: Comissão para Igualdade e para os Direitos das Mulheres, 2006.

GOELLNER, S. V.. O método francês e a educação física no Brasil: da caserna à escola. 1992. 215 f. Dissertação (Mestrado) - Escola Superior de Educação Física, Universidade Federal do Rio Grande do Sul, Porto Alegre, 1992.

. Mulheres e futebol no Brasil: entre sombras e visibilidades. Revista Brasileira Educação Física e Esporte, São Paulo, v. 19, n. 2, p.143-151, abr./ jun. 2005

GOELLNER, Silvana V.; FRAGA, Alex B. O espetáculo do corpo: mulheres e exercitação física no início do século XX. In: CARVALHO, Marie J. S.; ROCHA, Cristianne M. F. (Org.). Produzindo gênero. Porto Alegre: Sulina, 2004. p. 161169.

GUARESCHI, N. M. F.; MEDEIROS, P. F.; BRUSCHI, M. E. Psicologia social e estudos culturais: rompendo fronteiras na produção do conhecimento. In.: N. M. F. Guareschi e M. E. Bruschi (Org.) Psicologia social nos estudos culturais. Petrópolis: Vozes, 2003.

HALL, S. A identidade cultural na pós-modernidade. Rio de Janeiro: DP\&A, 2006.

Quem precisa de identidade? In: DA SILVA, T. T. (org). Identidade e diferença: a perspectiva dos Estudos Culturais. Petrópolis: Vozes, 2000.

HOBSBAWM, E. J. A era dos extremos: o breve século XX. São Paulo: Companhia das Letras, 2008. 
LOURO, G. L.. Gênero, sexualidade e educação: uma perspectiva pósestruturalista. Petrópolis: Vozes, 1997.

PINTO, C. R. J. Uma história do feminismo no Brasil. São Paulo: Fundação Perseu Abramo, 2003.

REGULAMENTO o 7 de Educação Física. Rio de Janeiro: Biblioteca da "a Defesa Nacional", 1934. Disponível em: <http://www.we3m.com.br/cev/regulamento/ fla01.htm>. Acesso em: 18 mar. 2009.

RUBIO, K. Medalhistas olímpicos brasileiros: histórias, memórias e imaginário. São Paulo: Casa do Psicólogo, 2006.

RUBIO, K.; SIMÕES, A. C. De espectadoras a protagonistas: A conquista do espaço esportivo pelas mulheres. Revista Movimento, Porto Alegre, v. 5, n. 11, p. 50-56, 1999.

SILVA, T. T. A produção social da identidade e a diferença. In: SILVA, T. (Org.). Identidade e diferença: a perspectiva dos estudos culturais. Petrópolis: Vozes, 2000.

Endereço para correspondência:

Centro de Estudos Socioculturais do Movimento Humano

Av. Professor Mello Moraes, 65, Bloco D, 4 andar

CEP: 05508-030, São Paulo - SP, Brasil

Recebido em: 01.07.2011

Aprovado em: 06.06.2012

Movimento, Porto Alegre, v. 18, n. 02, p. 255-275, abr/jun de 2012. 
